\title{
CONTRUIÇÕES DA EUROPA PARA O CONTROLE DE CONVENCIONALIDADE: PLURALISMO DE AVANÇOS E PROBLEMAS
}

\begin{abstract}
${ }^{1}$ Sérgio Tibiriçá Amaral
${ }^{2}$ Mário Coimbra

\section{RESUMO}

O Sistema Interamericano de Proteção aos Direitos Humanos utilizaram instrumentos nascidos na Europa como o controle de convencionalidade da Corte e da Comissão, aprimorando institutos. O pluralismo jurídico traz o controle não jurisdicional feito pela Comissão e pelo Brasil. No entanto, há problemas relativos como uma demora de até oito anos na apreciação dos casos. O órgão não jurisdicional tem rejeição de 98 por cento das petições. A Opinião Consultiva é novo controle que estabelece modelos, mas a ausência de alguns Estados e ainda, a não efetivação de algumas sentenças como o caso Guerrilha do Araguaia prejudicam o pluralismo.
\end{abstract}

Palavras-chave: Controle de convencionalidade, Comissão, Corte Idh, Pluralismo jurídico, Caso Gomes Lund vs. Brasil

\section{CONTRUIÇÕES DE EUROPA PARA EL CONTROL DE CONVENCIONALIDAD: LOS AVANCES Y PROBLEMAS EN PLURALISMO}

\section{RESUMEN}

El Sistema Interamericano de Protección de Derechos Humanos nació en Europa como el control de convencionalidad de la Corte y la Comisión, la mejora de los institutos. El pluralismo jurídico trae sin revisión judicial realizada por la Comisión y Brasil. Hay problemas relacionados con un retraso de hasta ocho años en el manejo de los casos. Corte Falla ha rechazado el 98 por ciento de las peticiones. La Opinión Consultiva está estableciendo nuevos modelos de control, pero la ausencia de algunos estados y la no realización de algunas frases en su caso Guerrilla Araguaia, podrían dañar el pluralismo

Palabras-claves: Control de convencionalidad, Comisión, Corte interamericana, El pluralismo jurídico, Gomes Lund vs. Brasil

\footnotetext{
1 Doutor em Sistema Constitucional de Garantias pela Instituição Toledo de Ensino - ITE, São Paulo (Brasil). Professor do Instituição Toledo de Ensino - ITE, São Paulo (Brasil). E-mail: sergio@ unitoledo.br

2 Doutor em Sistema Constitucional de Garantia de Direitos pelo Instituição Toledo de Ensino - ITE, São Paulo (Brasil). Professor do Centro Universitário Antônio Eufrásio de Toledo de Presidente Prudente, São Paulo (Brasil). E-mail: mcoimbra@terra.com.br
} 


\section{INTRODUÇÃO}

Os temas tratados são relativos ao pluralismo transnacional que traz uma normatividade para além do Estado por meios dos tratados regionais de direitos humanos. Há importantes contribuições oriundas da Europa que foram aperfeiçoadas no Sistema Interamericano de Proteção aos Direitos Humanos (SIPDH) formados pela Comissão e Corte IDH. Os dois órgãos aprimoraram os institutos europeus do controle de convencionalidade e buscaram soluções. Fica demonstrado que há problemas numa comparação com a Corte Europeia como a questão do acesso para pessoas na Corte. Há ainda problemas de efetividade das sentenças, que fica demonstrado no caso Gomes Lund Vs. Brasil. O pluralismo surge como uma opção para combater às violações dos direitos humanos, que envolve uma justiça nacional e a Organização dos Estados Americanos (OEA). As pesquisas são bibliográficas em livros nacionais e estrangeiros, mas também são utilizados dados dos sites dos órgãos de proteção. São usados os métodos dedutivo e indutivo dentro do material pesquisado.

Dentro desse pluralismo merece destaque o controle de convencionalidade em nível interno, ou seja, o realizado no Brasil, que no caso da prisão civil do depositário infiel foi efetivado pelo Supremo Tribunal Federal.

O controle internacional feito dentro do Sistema é feito pela Comissão e pela Corte Interamericana. Pode ser usado pelas pessoas dos países signatários da Organização dos Estados Americanos e tem como finalidade responsabilizar os Estadosmembros por violações dos direitos humanos. A Comissão, embora seja um órgão não jurisdicional, pode realizar a checagem das normas internas com os tratados de direitos humanos para os 35 Estados-membros. Mas muitas petições das pessoas não são acolhidas pelo órgão que fica em Washington.

O controle contencioso e consultivo na Corte IDH, por sua vez, somente vale para os 25 Estados ratificaram Convenção, que entrou em vigor em 1978, havendo a jurisdição facultativa. O modelo trazido da Europa foi aprimorado com uso da Opinião Consultiva, mas também um controle repressivo em nível nacional. No entanto, o controle por meio do contencioso tem um histórico de impugnação das leis internas dos Estados que violam os tratados de direitos humanos, como Última tentação de Cristo vs. Chile, entre outros. Com base em dispositivos europeus, o Sistema buscou e conseguiu aperfeiçoar a defesa dos direitos humanos no Continente, embora necessite de importantes mudanças na comparação com a Europa. 


\section{NA FRANÇA, NASCIMENTO DO CONTROLE DE CONVENCIONALIDADE}

O preâmbulo da Convenção Interamericana ou Pacto de San José da Costa Rica é importante para entender pluralismo jurídico presente no controle de convencionalidade, bem como princípios e fundamentos, os quais deverão pautar a interpretação de todos os demais dispositivos, bem como influenciar a legislação interna dos Estados-membros, como o Brasil. O SIPDH vinculado à Organização dos Estados Americanos(OEA) é composto de dois órgãos, a Comissão Interamericana de Direitos Humanos, que fica em Washington, nos Estados Unidos da América do Norte e a Corte Interamericana, que fica em San José da Costa Rica. O preâmbulo do Pacto diz que os direitos humanos devem ser analisados tendo como fundamento os atributos da pessoa humana, sendo, isso rege todos os demais dispositivos. Por outro lado, o artigo $1^{0}$ da Convenção (BRASIL,1992) fala da obrigação de respeitar direitos:

\footnotetext{
Os Estados- partes nesta Convenção comprometem-se a respeitar os direitos e liberdades nela relacionados e a garantir seu livre e pleno exercício a toda pessoa que esteja sujeita à sua jurisdição, sem discriminação alguma, por motivo de raça, cor, sexo, idioma, religião, opiniões políticas ou de qualquer outra natureza, origem nacional ou social, posição econômica, nascimento ou qualquer outra condição social.
}

Portanto, os Estados-Membros precisam efetivar direitos que nasceram de uma legitimidade diferente das leis infraconstitucionais brasileiras ou dos poderes constituintes dos membros. A base doutrinária do chamado controle de convencionalidade repousa no o caput do referido artigo, pelo qual os Estados-partes são obrigados a cumprir a Convenção independentemente do cumprimento pelos demais Estados. O artigo $2^{0}$ (BRASIL, 1992) afirma:

Dever de adotar disposições de direito interno. Se o exercício dos direitos e liberdades mencionadas no artigo 1 ainda não estiverem garantidos por disposições legislativas ou de outra natureza, os Estados-partes comprometem-se a adotar, de acordo com suas normas constitucionais e com as disposições desta Convenção, as medidas legislativas ou de outra natureza que forem necessárias para tornar efetivos tais direitos.

Os direitos e garantias expressos na Convenção devem servir de modelo aos previstos no direito interno. Mas, há ainda importante referência prevista no dispositivo que regula a assinatura dos tratados, que podem ser incorporados como leis no País, desde que ratificados e agora aprovados por quórum qualificado de quatro votações de $3 / 5$.

A Convenção de Viena sobre o Direito dos Tratados afirma que um Estado não pode se utilizar de uma norma interna para justificar o não cumprimento do tratado internacional, em especial de direitos humanos. O dispositivo reforça a Justiça 
supranacional e também o controle de convencionalidade. $\mathrm{O}$ artigo 46 determina que não seja permitido ao Estado contratante alegar a nulidade da adesão, caso este tenha violado alguma norma do Direito Interno.

Valério de Oliveira Mazzuoli (2013 p.152) defende a primazia do direito internacional, com base nos tratados dos quais o Brasil é signatário, o que significa reconhecer o primado do direito internacional dos direitos como limite ao exercício das competências dos Estados, justificando a necessidade desse pluralismo.

O controle de convencionalidade nasce na jurisprudência da Corte Europeia de Direitos Humanos e é adaptado para Corte IDH, como ressalta Nestor Pedro Sagúes(2015, p.348). Na década de 70, o Conselho Constitucional da França na decisão 74-54 DC cria importante e inovador precedente, mesmo se colocando como incompetente para apreciar preventivamente as leis diante dos tratados ratificados pela República francesa no âmbito da Convenção Europeia de Direitos Humanos. Ainda estava em curso o processo de unificação, com normas de Direito de Integração caminhado para o Direito Comunitário, que consolidaria o bloco da hoje União Europeia. Surge a tese de um controle das leis internas que teriam que se adequar aos tratados de direitos humanos. Portanto, o SIPDH americano usou o caso francês de 1975, que trazia a incompetência do Estado para analisar preventivamente as leis, ou seja, a compatibilidade das leis com os tratados assinados e ratificados pela França no âmbito da União Europeia. No entanto, nesse, o parâmetro foram usados dispositivos do Direito Comunitário, no caso a Convenção Europeia.

Como não há normas supranacionais nas Américas, essa questão de compatibilidade sofre alterações e aperfeiçoamentos no Sistema, na Comissão e na Corte IDH. Uma das novidades é a participação fundamental da Comissão, que dentro das suas alegações construiu importantes argumentos sobre a supremacia dos tratados na defesa dos direitos humanos. Esse órgão não judicial estabeleceu a supremacia das normas mais benéficas, ou seja, confirmou o princípio pro-homini, inclusive aceito no ordenamento brasileiro como prevalência dos direitos humanos.

Verifica-se um controle não-jurisdicional feito pela Comissão, que atinge

todos os membros da OEA, foi uma inovação do modelo europeu. Havendo conflito entre uma norma interna e outra internacional, prevalece a mais favorável.

Sérgio Garcia Ramirez (2005, p.1-86) explica a inspiração no caso francês, mas ressalta o aperfeiçoamento na jurisprudência do controle feito na comissão a partir do caso Última Tentação de Cristo Vs. Chile. Há a tentativa da derrogação de leis conflitantes com a Convenção ou reformas legislativas das mais diversas efetivadas na Corte. O autor cita a criação de programas de formação em direitos humanos e 
desenvolvimento social em comunidades que tiveram seus membros afetados por violações como outras contribuições.

As fontes para essa interpretação inspirada no modelo francês, segundo Adelina Goiano (2010, p.786) são: Estatuto e o Regulamento Interno da Corte Interamericana junto com a Convenção Americana dos Direitos Humanos e ainda as regras emanadas da jurisprudência da Corte. Os princípios são importantes, pois são vetores que alcançam os ordenamentos dos membros da OEA e, por isso, podem determinar o controle das normas internas com base nos tratados de direitos humanos.

Para Eduardo Andrés Velandia Canosa (2015, p.88) nos artigos 52 a 69 trazem os princípios do Pacto de São José, servem hoje para que a Comissão faça um tipo de juízo de admissibilidade, que pode pedir a invalidação de uma norma interna. Apesar da inspiração no modelo francês, a doutrina e a jurisprudência americana buscaram novas soluções, como esse controle não-jurisdicional.

Não se pode acessar a Corte sem passar pela Comissão, órgão que sofreu mudanças em 2010 e passou fazer juízo de admissibilidade. As petições na comissão podem ser feitas por qualquer pessoa, ONGs ou Estado, o que no dizer de Ernesto Ray Cantor(2010, p. 33) é uma estimulação externa.

A Comissão pode recomendar a revogação de uma norma interna e se for atendida, estamos diante de um tipo de controle de convencionalidade. Para uma denúncia, há necessidade de alguns requisitos.

Um deles é um princípio do esgotamento dos recursos internos nos julgamentos nacionais, previsto no art. 46 "a" da Convenção. É requisito de admissibilidade de uma petição ou comunicação a ser analisada pela Comissão. Na leitura do artigo vê-se que o esgotamento não é absoluto: ”a) não há devido processo legal; b) não se houver permitido o acesso aos recursos da jurisdição interna, ou houver sido impedido de esgotá-los; c) houve demora injustificada na decisão sobre o caso". Portanto, trata-se de justiça complementar. Desse princípio também chamado de complementaridade.

Há ainda na Comissão o princípio da proibição de retrocesso, que afirma que um direito declarado e aceito como universal ou inerente ao homem não pode dele ser subtraído pela legislação interna. O artigo. 4.4 é claro: "Não se pode restabelecer pena de morte nos Estados que a hajam abolido".

Brasil faz parte da Convenção por meio da promulgação feita pelo decreto 678, reconhecendo a competência contenciosa da Corte em 1998, por meio do Decreto Legislativo 89, estando sujeito aos deveres da Convenção.

Além da Carta da OEA, com seus Protocolos, e da Convenção Americana sobre Direitos Humanos, a Comissão Interamericana possui também estatuto e regulamento próprios, que são instrumentos básicos que disciplinam o funcionamento da instituição e o procedimento diante de uma denúncia de violação. Os tratados de direitos humanos que podem ser usados como controle de convencionalidade: Declaração Americana dos Direitos e Deveres do Homem; Pacto de San José da Costa Rica; Protocolo Adicional da Convenção Americana dos Direitos Humanos em matéria de Direitos Econômicos, Sociais e Culturais (Protocolo de San Salvador); Protocolo Adicional da Convenção 
relativo à abolição da Pena de Morte; Convenção Interamericana para Prevenção da Tortura; Convenção Interamericana Sobre Sequestro e Convenção Interamericana para Prevenir, Punir e Erradicar a Violência (Convenção de Belém do Pará).

\section{OS PROBLEMAS DA COMISSÃO}

Como órgão não jurisdicional da Organização dos Estados Americanos, a Comissão Interamericana de Direitos Humanos traz entre as suas atribuições "a promoção dos direitos humanos", embora existam algumas críticas importantes ao funcionamento e efetividade nessa etapa inicial do Sistema. Por levantamentos, as petições demoraram em torno de seis a oito anos para ser apreciadas, demora grande e prejudicial à efetividade dos direitos humanos, segundo levantamentos feitos Eduardo Andrés Velandia Canosa (2015, p. 92) e confirmados no site (http://www.oas.org/pt/cidh/).

Pelo dados do site da Comissão, apenas dois por cento dos pedidos são apreciados, ou seja, há uma rejeição de 98 por cento das solicitações. Isso pode gerar uma falsa expectativa para os peticionários.

Há ainda outra questão geográfica, que dificulta o pleno acesso à Justiça transnacional. A sede está localizada em Washington, o que dificulta o acesso dos mais necessitados. O ideal seria que houvesse um escritório para receber as petições nos 35 Estados-membros da OEA.

Embora exista uma incumbência de promover a observância e a defesa dos direitos humanos, na interpretação do parágrafo 23 , que estabelece certas atribuições da Comissão IDH, como fica claro na Opinião Consultiva OC-13/94 da Corte IDH, há falta de uma melhor estrutura.

No caso do controle de convencionalidade, a Comissão pode exercer um controle não jurídico, que terá de contar com a anuência do Estado denunciado por violações.

Citando os julgamentos do controle de convencionalidade nos casos Aguardo Alfaro e outros Vs. Peru (Trabajadores cessados del Congreso) fica claro que a Comissão deve negociar a revogação de uma lei ou ato.

O entendimento de que é possível esse controle é reforçado num caso envolvendo o Chile, no qual a Corte IDH afirma que todos os órgãos de supervisão da Convenção podem e devem nos casos concretos de violações dos direitos humanos determinarem uma compatibilidade ou não com a Convenção de qualquer ato e omissão por parte de qualquer poder e órgão ou agente do Estado, incluindo leis nacionais e sentenças de 
tribunais nacionais, o que está na sentença do caso Almonacid Arellano Vs. Chile.

Por isso nas sessões anuais, os "comissionados" podem exercer o controle de convencionalidade e ainda convocar sessões extras ou realizar visitas in loco aos Estados, a fim de averiguar aspectos referentes a casos específicos em trâmite. Nesse trabalho de elaborar relatórios sobre a situação geral dos direitos humanos nos países visitados, pode o órgão sugerir a revogação de normas internas.

Trata-se de órgão de solução de conflitos, embora outros afirmem que seja quasejurisdicional, como Ernesto Rey Cantor(2010, p. 18), pois ao elaborar uma recomendação de revogação de uma norma interna é uma função dessa natureza.

Hector Fix-Zamudio (2008, p.203) diz que a Comissão faz "instrução e a investigação das violações dos direitos humanos, antes do julgamento na Corte", reconhecendo que o Estado-membro pode acatar as recomendações antes do julgamento da Corte. Se o Estado-membro aceitar as recomendações de invalidar as normas nacionais, tendo como parâmetro os compromissos internacionais assumidos na proteção dos direitos humanos, fica configurado um controle não judicial.

\section{CORTE: CLÁUSULA RAUL FERNANDEZ E CONVENÇÃO EUROPEIA}

A Corte Interamericana de Direitos Humanos é um órgão judicial autônomo que fica em San José da Costa Rica, criado para aplicar e interpretar a Convenção Americana de Direitos Humanos e todos os demais os tratados de direitos humanos no âmbito das Américas. A ausência dos Estados Unidos da América do Norte, que assinou e não ratificou é uma ausência sentida, mas há outras como do Canadá, que sequer assinou ao tratado que cria o tribunal. E ainda há os que deixaram a Corte, pois o Pacto é passível de denúncia, como Haiti e Venezuela.

Há um problema de acesso, ou seja, de legitimidade de peticionar na Corte IDH numa comparação com a Corte Europeia de Direitos do Homem.

O artigo 61 diz que só os Estados-parte e a Comissão têm direito de submeter caso à decisão da Corte, sendo necessário esgotamento dos recursos internos. Por isso, os particulares e instituições privadas não podem ajuizar ações na Corte, diferente do que ocorre na Corte Europeia de Direitos Humanos, no qual os indivíduos passaram a ter capacidade postulatória.

Na Corte Europeia, segundo Luiz Flávio Gomes e Valério de Oliveira Mazzuoli (2010, p. 378), com a entrada em vigor do Protocolo n. 11 à Convenção Europeia dos Direitos Humanos, os indivíduos passaram a ter capacidade postulatória 
plena perante o Tribunal, o que ainda não é possível na Corte IDH.

O artigo 62.1, da Convenção versa sobre a chamada cláusula facultativa da jurisdição obrigatória, que permite que o Estado-parte manifeste se aceita ou não a competência contenciosa da Corte IDH em todos os casos relativos às soluções de controvérsias que se apresentam sobre a interpretação ou aplicação da Convenção.

Esta cláusula optativa também se encontra no artigo 36, 2, alíneas "a" a “d”, do Estatuto da Corte Internacional de Justiça, que é denominada "Raul Fernandes, por ter sido proposta no âmbito da Corte Internacional de Justiça por este internacionalista brasileiro" (MAZZUOLI, 2003, p.939).

A Corte IDH tem competência consultiva e contenciosa, como estipula também o art. 2 do Estatuto. Sua função jurisdicional é regida pelas disposições dos artigos 61, 62, e 63 da Convenção. E sua função consultiva se rege pelas disposições do artigo 64. Pode conhecer qualquer caso relativo interpretação ou aplicação das disposições do Pacto sempre que os Estados-partes tenham reconheçam sua jurisdição por declaração expressa especial.

A Corte é composta por sete juízes, nacionais dos Estados - Membros da OEA, eleitos a título pessoal entre juristas da mais alta autoridade moral, de reconhecida competência em matéria de direitos humanos, que reúnam as condições requeridas para o exercício das mais elevadas funções judiciais. Não deve haver dois juízes da mesma nacionalidade pelo art.52. A votação é secreta, pelo voto da maioria absoluta, na Assembleia Geral, a partir de uma lista de candidatos proposta (art.53). Os magistrados terão mandato de seis anos e só poderão ser reeleitos uma vez.

O quórum para as deliberações da Corte é constituído por cinco juízes (art.56). As decisões da Corte serão tomadas pela maioria dos juízes presentes. Em caso de empate, o Presidente terá o voto de qualidade.

Como ressalta Boris Barrios Gonzales (2015, p.47), a Corte desde suas primeiras sentenças em 1988 até o início de 2015, se pronunciou sobre o tema de proteção a integridade e liberdade pessoal em sessenta e sete casos contenciosos, trinta e uma medidas provisionais e seis opiniões consultivas.

Na sentença será declarada a responsabilidade internacional do Estado e, consequentemente, serão formuladas as recomendações correspondentes ao Estado, para que no prazo de três meses aceite a decisão e faça as reparações integrais em favor das vítimas e/ou seus familiares pelos danos causados que podem ser as seguintes: Restituição dos direitos humanos; Indenização; Danos materiais: Dano emergente; 
Lucro cesante; Danos imateriais; Medidas satisfativas; Medidas de reabilitação; Medidas de não repetição; Dano ao projeto de vida.

Para Ernesto Ray Cantor (2010, p. 27) às vezes são necessárias medidas cautelares, antes das decisões de fundo, quando os argumentos jurídicos ordenam reparações integrais que correspondem a determinar que o Estado faça reparações para as vítimas ou familiares, como indenizações por dano materiais emergentes e cessantes, danos imateriais, medidas satisfativas como pagamento de multas, de reabilitação com devolução de bens e outros.

\section{CONTROLE: ORIGEM NA CORTE INTERNACIONAL DE JUSTIÇA}

Entende-se por controle de convencionalidade internacional aqueles que são feitos no âmbito do Sistema (SIPDH), composto da Comissão e da Corte IDH, sendo este último feito nas duas competências, consultiva e contenciosa.

Segundo autores como Eduardo Andrés Velandia Canosa (2015, p. 91), Ignacio Herrerías Cuevas e Marcos Del Rosário Rodríguez (2012, p. 37), esse tipo de controle tem origem na Corte Internacional de Justiça, no caso de intercâmbio de populações gregas e turcas, quando ficou claro na sentença que se um Estado contraiu validamente obrigações internacionais está obrigado a introduzir na sua legislação as modificações que sejam necessárias para assegurar a execução dos compromissos contraídos. A doutrina foi ratificada no julgado da Corte Internacional de Justiça envolvendo as populações de origem polonesa citado por Antônio Augusto Cançado Trindade (2008, p. 30).

Trata-se de um processo transacional que tramita na Corte, um conjunto de atos sucessivos e pré-ordenados, encaminhados a proferir uma sentença de fundo que solucione definitivamente um conflito definindo a supremacia de uma norma e protegendo os direitos humanos (VELÂNDIA CANOSA, 2015, p.91).

Há alguns autores que fazem classificação sobre o controle como Edgar Andrés Quiroga Natale (2015, p.87). Para ele o controle concentrado é exercido pela Corte IDH, que é um órgão criado pelo Pacto para defender os direitos previstos no próprio tratado, enquanto que o difuso é das autoridades internas de cada Estado-membros.

Victor Bazán (2003, p.20) chama de natureza convencional coadjuvante ou complementar aos ordenamentos nacionais, como está no parágrafo 2 . do preâmbulo da Convenção, mas também reconhece os dois controles.

Na Argentina o artigo 2. da Lei n. 23.054/84, que aprovou internamente o Pacto de San José no ordenamento interno, afirma que as decisões com base na Convenção, 
sentenças, opiniões consultivas também são de aplicação obrigatória naquele país, tanto pelas autoridades nacionais, como pelas províncias e municípios, segundo Martha Helia Altabe Lertora (2008p. 251).

O tribunal das Américas pode conhecer qualquer demanda por violação de direitos humanos ou fatos e atos internacionalmente ilícitos e ainda interpretar as disposições incorporadas pelo Pacto, o que fica demonstrado nas decisões da Corte IDH nos casos Chaparro Álvarez Vs. Equador e Yvón Neptune Vs. Haiti.

O controle de convencionalidade surge como um direito transnacional, onde estão juntos o direito constitucional processual e o direito processual constitucional, no qual há uma confrontação entre a Convenção e uma disposição do direito interno, segundo Eduardo Andrés Velandia Canosa (2014, p. 117).

$\mathrm{O}$ controle internacional da Corte IDH na jurisprudência foi em parte estruturada pelo juiz Sergio Garcia Ramires, que comparou o trabalho do tribunal diante do Pacto ao desempenhado pelas cortes constitucionais no seu voto julgamento Tibi Vs. Equador, de 7 de setembro de 2004. Para Ramires, a função foi de checar às normas locais com a ordem internacional do Pacto dentro de jurisdição supranacional aceita pelos Estados. Citando o caso francês e outros julgamentos na Europa, construiu a doutrina. As sentenças pioneiras no controle de convencionalidade são: Lacayo Vs. Nicarágua, Última Tentación de Cristo (Olmedo Bustos y otros) Vs. Chile, Myrna Chang Vs. Guatemala e Almonacid Arellano Vs. Chile.

"Ultima Tentação de Cristo Vs. Chile” é um julgamento contencioso de Olmedo Bustos contra uma censura envolvendo o Conselho de Qualificação Cinematográfica do Chile, que vetou a exibição do filme “A Última Tentação de Cristo". O julgamento determinou que o Chile revogasse a lei que censura o filme, além de impor reparações Mas, ainda há outros casos de controle das normas internas: El Amparo Vs. Venezuela, Caballero Delgado Vs. Colômbia, Castilllo Pàez Vs. Peru, Suarez Romero Vs. Equador, Castillo Petruzzi e outros Vs. Colômbia, "Barrios Altos" Vs. Peru, Periódico "La Nacion” Vs. Costa Rica, Caesar Vs. Trinidad e Tobago, Fermin Ramírez Vs. Guatemala e Raxcacó Reys vs. Guatemala.

Nos casos, a Corte IDH reafirmou que existe responsabilidade internacional do Estado pela elaboração e aplicação de leis violadoras da Convenção, como está nos artigos 1 e 2, como ficou claro na Opinião Consultiva 14/94 no caso Lacayo Vs. Nicaraguá. Portanto, uma nova contribuição com o controle por meio de uma interpretação dos tratados. 
O controle é função principal, como revela Eduardo Ferrer Mac-Gregor(2012, p.41), pois a Corte de resolve os casos que são submetidos à sua jurisdição, como guardião e último interpréte da Convenção.

Portanto, as espécies normativas primárias previstas no artigo 59 da Constituição do Brasil e outras leis podem ser confrontadas na Corte, pois os Estados-Partes tem o dever de adotar em suas disposições de direito interno da citada convenção.

O controle se concretiza com uma sentença proferida pelo tribunal localizado na Costa Rica, que determina a modificação, revogação, anulação ou reformas de normas ou mesmo políticas executivas internas, visando proteger os direitos humanos. Portanto, em tese, o campo material do controle no Brasil são leis ou atos normativos em nível federal, estadual e municipal, pois a Colômbia também aceita espécies normativas estaduais e municipais.

\section{A LEI DA ANISTIA NO CONTROLE CONCENTRADO}

Inicialmente, necessário se faz ressaltar que esse controle não se mostrou efetivo no caso importante envolvendo o Brasil, Gomes Lund e outros vs. Brasil, na qual a Corte fez coisa julgada convencional, que não foi acatada. Ao contrário, houve uma "auto anistia" para crimes de lesa humanidade, o que é incompatível com os princípios do Sistema e proibido pela Convenção de Viena dos Direitos dos Tratados, no artigo 2.7. O não cumprimento das decisões da Corte IDH traz questionamentos importantes.

A sentença da Corte IDH (Caso Gomes Lund y otros - Guerrilha do Araguaia Vs. Brasil, 2010, par. 325.3, p. 113) em seus pontos resolutivos, decidiu, por unanimidade que as disposições da Lei da Anistia:

[...] impedem a investigação e sanção de graves violações de direitos humanos são incompatíveis com a Convenção Americana, carecem de efeitos jurídicos e não podem seguir representando um obstáculo para a investigação dos fatos do presente caso, nem para a identificação e punição dos responsáveis, e tampouco podem ter igual ou semelhante impacto a respeito de outros casos de graves violações de direitos humanos consagrados na Convenção Americana ocorridos no Brasil. (grifo nosso)

Com base no parágrafo 325.4-7 da sentença, declarou que o Brasil:

[...] é responsável pelo desaparecimento forçado e, portanto, pela violação dos direitos ao reconhecimento da personalidade jurídica, à vida, à integridade pessoal e à liberdade pessoal, estabelecidos nos artigos $3,4,5$ e 7 da Convenção Americana sobre Direitos Humanos, em relação com o artigo 1.1 desse instrumento, em prejuízo das pessoas indicadas no parágrafo 125 da presente Sentença, em conformidade com o exposto nos parágrafos 101 a 125 da mesma. 
Por outro lado, a Lei da Anistia foi objeto de Arguição de Descumprimento de Preceito Fundamental (ADPF) $n^{\circ} 153$, a qual foi proposta pelo Conselho Federal da Ordem dos Advogados do Brasil, “objetivando a declaração de não-recebimento, pela Constituição do Brasil de 1988 , do disposto no $\S 1^{\circ}$ do artigo $1^{\circ}$ da Lei n. 6.683, de 19 de dezembro de 1979”. Julgada em 29 de abril de 2010, em momento posterior ao oferecimento da denúncia pela Comissão a Corte IDH, sendo que o STF, por 7 (sete) votos a favor e 2 (dois) votos contra, considerou recepcionado o disposto no $\S 1^{\circ}$ do artigo $1^{\circ}$ da Lei n. 6.683, de 19 de dezembro de 1979 pela norma suprema brasileira.

Por conta dessa decisão interna, o Brasil ainda não acatou a sentença de controle e invalidação da Lei da Anistia.

No caso Guerrilha do Araguaia, a Corte IDH determina que Lei de Anistia seja revogada, com base nos tratados e na jurisprudência nos casos Manuel Cepeda Vargas Vs. Colombia, e ainda Cabrera García e Montiel Flores Vs. México.

A principal fonte da jurisprudência estabeleceu que "os juízes e órgãos em todos os níveis tem a obrigação de exercer ex-ofício um controle de convencionalidade entre as normas internas e a Convenção, dentro das suas competências”. Há soluções para essa questão de desobediência da decisão da Corte IDH, mas que não são objeto do para esta apreciação acadêmica, mas que poderiam passar pelo controle interno.

\section{O CONTROLE DE CONVECIONALIDADE INTERNO NO BRASIL}

Por controle interno se entende todos os mecanismos usados no Brasil, a saber, os preventivos e os repressivos, a fim de checar se as leis ou atos federais, estaduais e municipais estão de acordo com os tratados de direitos humanos do Pacto. Para tanto, ou seja, há um confronto material que pode usar controle difuso ou mesmo o concentrado ou via de ação para checagem de parâmetros. Os dois dispositivos poderiam ser utilizados para que o Supremo voltasse a apreciar a questão da Lei da Anistia, mas pelo controle repressivo, em especial o concentrado.

A dupla checagem vertical no País deve ser feita inicialmente durante o processo legislativo, no chamado controle preventivo do Legislativo, do Executivo e do Judiciário. Portanto, as Comissões de Constituição e Justiça da Câmara e do Senado podem emitir "pareceres" de controle de convencionalidade, enquanto que o Presidente da República pode utilizar o veto jurídico para afastar uma norma federal que viole tratados de direitos humanos.

Surge um novo tipo de veto com fundamento na contrariedade do projeto aos tratados de direitos humanos da OEA, que também é veto jurídico, mas com 
fundamento diferente na sua justificativa, pois levada em contra a supra legalidade dos tratados. Porém esse veto não é absoluto, podendo ser derrubado por maioria absoluta do Legislativo. Depois da sanção presidencial ocorre a promulgação e publicação da lei, encerrando-se o controle preventivo.

Completando o controle preventivo, se a lei atentar contra uma "cláusula pétrea" prevista num tratado, um parlamentar pode buscar o Supremo Tribunal Federal para por meio de um mandado de segurança evitar essa discussão. É o chamado direito função.

Como é firmado pela doutrina na interpretação do parágrafo 2. do artigo 5., os direitos expressos não excluem outros que estão nos tratados internacionais, com possibilidade de direitos e garantias individuais nos tratados, o Supremo pode impedir à discussão de projeto de lei que viole essa parte do núcleo imodificável no tocante a subtração de direitos previstos em tratados de direitos humanos.

Depois da lei em vigor, começa o controle repressivo que é no Judiciário. No chamado controle difuso interno, há um importante precedente firmado em 22 de novembro de 2006, no julgamento do Recurso Extraordinário 466.343, em que o Ministro Gilmar Mendes proferiu:

(...) a reforma acabou por ressaltar o caráter especial dos tratados de direitos humanos em relação aos demais tratados de reciprocidades entre Estados pactuantes, conferindolhe lugar privilegiado no ordenamento jurídico. (...) a mudança constitucional ao menos acena para insuficiência da tese da legalidade ordinária dos tratados já ratificados pelo Brasil, a qual tem sido preconizada pela jurisprudência do Supremo Tribunal Federal desde o remoto julgamento do RE n. 80.004/SE, de relatoria do Ministro Xavier de Albuquerque (jugado em 1.06.1997) e encontra respaldo em largo repertório de casos julgados após o advento da Constituição de 1988 (...).

A via difusa, também denominada de exceção, de defesa ou indireta, é, em síntese, a arguição da incompatibilidade de um ato normativo ou lei, dentro de um processo judicial comum, frente às normas do Pacto de San José da Costa Rica. Nesse sentido, os juízes nacionais tem a obrigação não só de aplicar as normas domésticas, mas também as de índole internacional desde que as partes as exijam (VELÂNDIA CANOSA, p.61).

Por sua vez, a via concentrada, também chamada de direta, ou de ação ou ainda de controle abstrato são ações com a finalidade única: a declaração de uma norma como nula por violação de um tratado internacional de direitos humanos. O artigo 97 da Constituição institui a cláusula da reserva de plenário, estabelecendo que, tanto pela via difusa quanto pela concentrada, a declaração desse novo tipo de nulidade deve ser pelo 
voto da maioria absoluta de seus membros ou do respectivo órgão especial.

No caso do controle difuso, o Supremo julgou o caso da alienação fiduciária e a não devolução do bem - depositário infiel - previa o artigo 652 do Código Civil, em pertinência com o artigo $5^{0}$, inciso LXVII da Constituição:

Art. 652. Seja o depósito voluntário ou necessário, o depositário que não restituir quando exigido será compelido a fazê-lo mediante prisão não excedendo a um ano, e ressarcir os prejuízos.

O controle repressivo no Brasil trouxe como primeiro caso a proibição da prisão civil do depositário infiel prevista como possibilidade no art. 5 LXVII que confrontava com o art. 7.7 da Convenção, que diz: "Ninguém deve ser detido por dívida". Este princípio limita os mandamos de autoridade judiciária competente expedidos em virtude de inadimplemento de obrigação alimentar.

Assim sendo, no tocante a prisão civil, o artigo $7^{0}, 7$ do Pacto de São José da Costa Rica determina que: "Ninguém deve ser detido por dívidas". Este princípio não limita os mandados de autoridade judiciária competente expedidos em virtude de inadimplemento de obrigação alimentar.

Da interpretação do referido dispositivo legal, tem-se que a Convenção Interamericana sobre Direitos Humanos somente admite a hipótese de prisão civil (meio coercitivo de pagamento) em caso de descumprimento de obrigação alimentícia, enquanto que, como exposto em linhas anteriores, a Constituição admite a prisão em duas hipóteses: descumprimento de obrigação alimentícia e ainda, no caso de depositário infiel. Assim, é patente o conflito existente entre a Lei Fundamental e ordinária pátria e a Convenção Americana.

No tocante ao controle concentrado não há dúvida que a Ação Direta de Inconstitucionalidade, a Ação Declaratória de Constitucionalidade e a Arguição de Descumprimento de Preceito Fundamental podem ser usadas pela invalidar as espécies normativas primárias previstas no artigo 59, leis estaduais, municipais, atos e até normas anteriores a 1988 que violem tratados de direitos humanos. No entanto, cada ação tem seu campo material próprio, sendo que leis municipais e a teoria da recepção somente podem ser alvo de ADPF.

Será denominado como via de ação, uma vez que deve existir uma provocação por parte dos legitimados do artigo 103, que colocam em movimento a jurisdição.

Para Corte IDH, o controle de convencionalidade é um dever por parte dos tribunais locais, não podendo ser afastado por qualquer pretexto, segundo Valério de Oliveira Mazzuoli (2015, p. 137). 
Se como ficou claro na prisão do depositário infiel julgado pelo STF e nas sentenças da Corte IDH, qualquer Juiz ou Tribunal do Brasil pode não aplicar uma lei que confronta a Convenção, dando aplicação direta ao tratado de direitos humanos.

\section{CONCLUSÕES}

Do exposto, infere-se que o Sistema de Proteção Interamericano de Direitos Humanos é de grande importância para proteção dos direitos do homem, funcionando o controle de convencionalidade como um fiscal da respeitabilidade por parte dos Estados-parte da OEA em relação aos direitos que eles se obrigaram proteger.

Há algumas importantes contribuições feitas para a construção e aprimoramento do sistema, que ficam explicadas, como o nascimento do controle num caso francês, bem como outras decisões importantes efetivadas na Corte Internacional de Justiça, da Organização das Nações Unidas.

Pelas análises feitas fica claro que se trata de uma instância superior, supranacional, que visa à aceleração da proteção por um mecanismo de âmbito internacional.

A construção da doutrina e da jurisprudência do controle teve como base decisões em outros tribunais, mas evoluiu como ao permitir o controle de convencionalidade feito pela Comissão Interamericana, órgão não-jurisdicional.

Em relação aos dispositivos da Corte Internacional de Justiça, a Corte IDH ampliou e aprimorou o sistema de proteção, em especial nos julgamentos citados de controle de convencionalidade, com participação especial de Sérgio Ramirez.

A Opinião Consultiva surge como outra construção feita pelos magistrados da Corte, que tem alguma eficiência num novo tipo de controle. Trata-se de uma interpretação autêntica dos compromissos assumidos pelos Estados com os tratados de direitos humanos.

O Sistema funciona com dois órgãos, sendo um não-jurisdicional e outro jurisdicional de proteção complementar aos direitos humanos nos países da OEA. A comissão faz juízo de admissibilidade e também controle, mas apresenta alguns problemas como demora e um número grande de petições rejeitadas.

$\mathrm{Na}$ Corte há um exame jurisdicional de compatibilidade dos atos normativos nacionais, bem como as sentenças proferidas pelo Judiciário, tomando como parâmetro a Convenção e seus Protocolos Adicionais, além da jurisprudência da Corte IDH. Modelo surgido na França foi aprimorado, embora apresente problemas.

O tribunal avançou no controle ao interpretar as disposições dos tratados de direitos humanos nos casos consultivos. Se o Estado-membro acata suas 
recomendações, há um tipo de controle preventivo. Isso foi aprimorado em relação ao sistema europeu.

No entanto, há problemas na comparação feita, pois o tribunal da Europa permite livre acesso às pessoas, o que no atual sistema só é possível no chamado controle interno e difuso de convencionalidade brasileiro.

Poderia ser ampliada a legitimidade para ingresso na Comissão, bem como serem criados escritórios regionais em cada um dos Estados-membros, a fim de facilitar o acesso, bem como tonar mais rápidos os julgamentos.

Outras questões merecem apreciação como o alto número de petições recusadas na Comissão, bem como a demora excessiva nas apreciações dentro desse órgão inicial, que acaba refletindo no tempo julgamento feito depois de seis oito anos.

\section{REFERÊECIA}

ALTABE DE LERTORA, Martha Helia. Control de convencionalidad <in〉 Revista Debates de Actualidade, n. 200, Buenos Aires: Asociación Argentina de Derecho Constitucional, 2008.

ANNONI, Danielle. Direitos humanos \& acesso à justiça no direito internacional: responsabilidade internacional do Estado. Curitiba: Juruá, 2003.

AYALA CORAO, Carlos M. Las modalidades de las sentencias de la Corte Interamericana de Derechos Humanos 〈in> FERRER MAC-GREGOR, Eduardo y ZALDÍVAR LELO DE LARREA, Arturo (coordinadores). La ciência Del derecho procesal constitucional, Tomo IX, Madrid: Marcial Pons/UNAM IIJ xd la UNAN, 2008.

BARROSO, Luís Roberto. Interpretação e aplicação da constituição. 2. ed. São Paulo: Saraiva, 1998.

$O$ direito constitucional e a efetividade de suas normas: limites $e$ possibilidades da constituição brasileira. 4. ed. Rio de Janeiro: Renovar, 2000.

BARRIOS GONZÁLES Boris, El control difuso de convencionalid em la tutela a jurisdicional de la libertade personal <in> Derecho Constitucional Convencionalizado y Justicia Constitucional <in> Derecho Procesal Constitucional, Bogotá: EC Editores, 2015.

BAZÁN, Víctor (Org.). Defesa de la Constitución: Garantismo y Controles. Buenos Aires: Ediar, 2003.

BLINDER, Richard B. An Overview Of International Human Rights Law. 2. ed. Philadelphia: University of Pennsylvania Press, 1992. 
BOBBIO, Norberto. A era dos direitos. Rio de Janeiro: Campus, 2004.

CANÇADO TRINDADE, Antônio Augusto. Tratado de direito internacional dos direitos humanos. 1. ed. Porto Alegre: Fabris, 1997-2003. 3 v

------.Evolution du droit international ao droit de gens: l'accès des individus à la justice internationale, Paris: A. Pedone, 2008.

CARVALHO, Júlio Marino de. Os direitos humanos no tempo e no espaço: visualizados através do direito internacional, direito constitucional, direito penal e da história. Brasília: Brasília Jurídica, 1998.

COMPARATO, Fábio Konder. A afirmação histórica dos direitos humanos. 6. ed., rev. e atual. São Paulo: Saraiva, 2008.

CONDE, Fernando Jiménez (coord.). Tutela jurisdicional de los derechos fundamentales. Murcia: Diego Marín Librero-Editor, 2002.

FERRER MAC-GREGOR, Eduardo (Coordinador). El control difuso de convencionalidad, Santiago de Querétaro: FUNDAP, 2012.

------. Interpretación conforme y control difuso de convencionalid, El nuevo paradigma para el juiz mexicano, Instituto de Investigacion jurídicas de la Universidad Nacional Autonoma de México, Ciudad de México, 2011.

FIX-ZAMUDIO, Héctor. Reflexões comparativas sobre los sistema interamericano y europeo de protección de los derechos humanos <in〉 Derecho Internacional de los Derechos Humanos. Cultura y Sistemas Jurídicos Comparados, (Méndez Silva coordenador). Cidade do México: Instituto de Investigações Jurídicas, 2008.

Los derechos humanos y su protección internacional, Lima: Grijley, 2009.

GOMES, Luiz Flávio; MAZZUOLI, Valério de Oliveira. Comentários à convenção americana sobre direitos humanos: Pacto de San José da Costa Rica. 2. ed., rev., atual. e ampl. São Paulo: Revista dos Tribunais, 2009.

------.Direito supraconstitucional: do absolutismo ao estado constitucional e humanista de direito. São Paulo: Revista dos Tribunais, 2010.

GOMES, Luiz Flávio; PIOVESAN, Flavia; TRINDADE, Antônio Augusto Cançado; DULITZKY, Ariel E.; GALLI, Maria Beatriz; MELO, Mônica de; PFEIFFER, Roberto Augusto Castellanos; KRSTICEVIC, Viviana. O sistema interamericano de proteção dos direitos humanos e o direito brasileiro. São Paulo: Revista dos Tribunais, 2000.

GOZAÍNI, Osvaldo Alfredo. El processo transnacional. Buenos Aires; Ediar, 1992.

------.Derecho Procesal Constitucionsl - Debido Proceso.Buenos Aires: Santá Fé, 2004.

HERRERÍAS CUEVAS, Ignacio F.; DEL ROSÁRIO RODRÍGUEZ, Marcos. El control de constitucionalidade y convencionalidad, México: Editorial Ubijos, 2012.

HITTERS, Juan Carlos. Control de Constitucionalidade y Control de 
Convencionalidade: Comparación (Criterios Fijados por la Corte Interamericana de Derechos Humanos), Estudios Constitucionales, ano 7. N.2, Universedad de Talca, 2009.

LEDESMA, Héctor Faúndez. El agotamento de los recuros internos em El Sistema de Protección de los derechos humanos, São José da Costa Rica, Instituto Interamericano de Derechos Humanos, 2007.

LLORENTE, Francisco Rubio. Derechos fundamentales y princípios constitucionales. Barcelona: Editorial Ariel, 1995.

LOIANO, Adelina. El proceso ante la Corte Interamericana de Derechos Humanos <in> MANILI, Pablo Luis (Director). Tratado de Derecho Procesal Constitucional, Tomo III, Buenos Aires: La Ley, 2010.

LUÑO, Antonio Enrique Pérez. Derechos humanos, estado de derecho y constitución. Madrid: Tecnos, 2003.

La universalidad de los derechos humanos y El estado constitucional. Bogotá: Universidad Externado de Colombia, 2002.

MARTOS, José A. Montilla. Minoria política \& tribunal constitucional. Madrid: Trotta, 2002.

MAZZUOLI, Valério de Oliveira. Direitos humanos \& cidadania: à luz do novo direito internacional. Campinas: Minelli, 2002.

Curso de direito internacional público. 3 e 4. ed., rev., atual. e ampl. São Paulo: Revista dos Tribunais, 2009 e 2010.

--------. Coletânea de direito internacional, Convenção Americana Sobre Direitos Humanos (1969), São Paulo: Revista dos Tribunais, 2010.

O Controle Jurisdicional da Convencionalidade das Leis, São Paulo: Editora Revista dos Tribunais, 2013.

MONTERISI, Ricardo D. Actuación y procedimiento ante la Comisión y Corte Interamericana de Derechos Humanos, La Plata: Libreria Editorial Platense, 2009.

MORELOS, Gumesindo García. El Control Judicial Difuso de Convencionalidad de los Derechos Humanos por los Tribunais Ordinarios em Mexico. D.C.: Ubijus, 2010.

MOYA DOMÍNGUEZ, Maria Teresa y VILLARREAL, David. Comisión Interamericana de Derechos Humanos <en> Tratados de los Tratados Internacionales. (CARNOTA, Walter F. y MARANIELLO, Patrício Alejandro (directores); LEONTINA SOSA, Guillermina \{coordinadora\}), Tomo II. Buenos Aires: La Ley, 2011.

NEGRI, Antonio. O poder constituinte: ensaio sobre as alternativas da modernidade. Rio de Janeiro: DP\&A Editora, 2002.

PARDO POSADA, Nohora Elena; HERNÁNDEZ DÍAZ, Carlos Arturo. Las decisicones de los organos internacionales, El bloque de constitucionalidad y su incidência em El derecho interno <in> Derecho Procesal Constitucional (coordinador: 
Eduardo Andrés Velandia Canosa), Tomo II, Volumen II, Bogotá: Agencia Imperial, 2011.

PEREZ TREMPS, Pablo. Las garantias constitucionales y la jurisdicción internacional em la protección de los derechos fundamentales, Anuário de la Facultad de Derecho, n. 10 Universidade de Extremadura.

PIOVESAN, Flavia. Direitos humanos e o direito constitucional internacional. 9. ed., rev., ampl. e atual. São Paulo: Saraiva, 2008.

QUIROGA NATALE, Edgard Andrés. Tipicidad Constitucional y Control de Convencionalid em Colombia a partir de 1991. Nociones Elementares <in〉 Derecho Procesal Constitucional Derecho Constitucional Convencionalizado y Justicia Constitucional <in> Derecho Procesal Constitucional, Bogotá: VC Editores Ltda, 2015.

RAMIRES, SÉRGIO GARCÍA. La jurisprudência de la Corte Interamerciana de Derechos Humanos em matéria de reparaciones. La Corte Interamericana de Derechos Humanos: um quarto de siglo (1979-2004). San José: CIDH, 2005.

RAY CANTOR, Ernesto. Acesso Sistema Interamericano de Derechos Humanos. Bogotá: Colômbia, 2010.

RUSSOMANO, Gilda Maciel Corrêa Meyer. Direitos humanos. Curitiba: Juruá, 1992.

SANGÚES, Nestor Pedro Sagúes. El control de convencionalidad em el sistema interamericano y sua aticipos em El âmbito de los derechos econômico-sociales: concordâncias e diferencias em el sistema europeo. Diponível em HTTP://.juridicas.unam.mx, 2015.

SARLET, Ingo Wolfgang. Dignidade da pessoa humana e direitos fundamentais na constituição federal de 1988. 2. ed. Porto Alegre: Livraria do Advogado, 2002.

STRECK, Lenio Luiz. Hermenêutica jurídica $e(m)$ crise. Porto Alegre: Livraria do Advogado, 2000.

TRUCCO, Marcelo F. La protección transnacional de los derechos humanos. El valioso aporte de la Corte Interamericana $\langle$ in $\rangle$ Tratado de los tratados internacionales,(CARNOTA, Walter F. y MARANIELLO, Patrício Alejandro (directores); LEONTINA SOSA, Guillermina \{coordinadora\}), Tomo II. Buenos Aires: La Ley, 2011.

VELANDIA CANOSA, Eduardo Andrés. La Justicia Constitucional y sua modelo transnacional <in> Derecho Procesal Constitucional, Tomo III, Volumen I, Bogotá: VC Editores Ltda, 2012.

-Derecho Constitucional Convencionalizado y Justicia Constitucional <in> Derecho Procesal Constitucional, Bogotá: VC Editores Ltda, 2015.

ZAGREBELSKY, Gustavo. El derecho dúctil. Madrid: Editorial trotta, 1995. 